\title{
Association of the Monocyte to HDL Cholesterol Ratio with Thrombus Burden in Patients with Acute Coronary Syndrome
}

\author{
Ghada Mahmoud Soltan1, Neveen I. Samy1, Safwat Essam Ahmed2, \\ Wassam ElDin Hadad ELShafey ${ }^{1}$ \\ ${ }^{1}$ Department of Cardiology, Menoufia University Hospitals, Menoufia, Egypt \\ ${ }^{2}$ Department of Cardiology, National Heart Institute, Cairo, Egypt \\ Email: safwatessam2016@gmail.com
}

How to cite this paper: Soltan, G.M., Samy, N.I., Ahmed, S.E. and ELShafey, W.E.H. (2019) Association of the Monocyte to HDL Cholesterol Ratio with Thrombus Burden in Patients with Acute Coronary Syndrome. World Journal of Cardiovascular Diseases, 9, 746-758.

https://doi.org/10.4236/wjcd.2019.910067

Received: September 13, 2019

Accepted: October 20, 2019

Published: October 23, 2019

Copyright $\odot 2019$ by author(s) and Scientific Research Publishing Inc. This work is licensed under the Creative Commons Attribution International License (CC BY 4.0).

http://creativecommons.org/licenses/by/4.0/

(c) (i) Open Access

\begin{abstract}
Background: Intracoronary thrombus burden is associated with some adverse events and poor prognosis in patients with Acute Coronary Syndrome. Identifying predictors of the intracoronary thrombus burden may contribute to the management of Acute Coronary Syndrome. Objective: To assess the correlation between the Monocyte to HDL Cholesterol ratio with thrombus burden in patients with Acute Coronary Syndrome. Patients and Methods: 138 patients with ACS who were admitted to CCU department in National Heart Institute Cairo and Menoufia University Hospitals, Menoufia, underwent primary percutaneous coronary intervention (PCI). Angiographic thrombus burden was classified based on thrombolysis in myocardial infarction (TIMI) thrombus grades. The patients were grouped into 2 categories of low thrombus burden (grades 0 - 3) (49.7\%) and high thrombus burden (grades 4 and 5) (50.3\%). Results: On analysis we found that the MHR was significantly higher in the high thrombus burden group compared with the low thrombus $(0.052 \pm 0.019$ vs $0.014 \pm 0.008) ; \mathrm{P}<0.001$. Conclusion: Among Acute Coronary Syndrome patients underwent Primary PCI, MHR was independent predictor of high thrombus burden in patients with Acute Coronary Syndrome.
\end{abstract}

\section{Keywords}

Monocyte to HDL Ratio, Acute Coronary Syndrome, Thrombus Burden

\section{Introduction}

Intracoronary thrombus formation due to atherosclerotic plaque rupture and the interruption of coronary blood flow constitute the main pathophysiology un- 
derlying acute coronary syndrome. The quantity of the intracoronary thrombus burden is associated with a poor prognosis in patients with Acute coronary syndrome [1] [2] [3].

Intracoronary thrombus management is still complex, although many pharmacological and invasive treatments have been developed, such as glycoprotein IIb/IIIa antagonists and thrombectomy. Identifying predictors of the intracoronary thrombus burden may contribute to the management of patients with acute coronary syndrome. Recently, the red cell distribution width (RDW) and bilirubin level were shown to predict the thrombus burden in patients with ACS [4] [5].

In this study, we aimed to assess the correlation between the Monocyte to HDL Cholesterol ratio (MHR) with thrombus burden in patients With ACS.

\section{Patients and Methods}

138 patients with ACS JUNE 2018 to APRIL 2019 who were admitted to CCU department in National Heart Institute Cairo and Menoufia University Hospitals, Menoufia, underwent primary percutaneous coronary intervention (PCI). Inclusion criteria the diagnosis of ACS was based on the criteria of the Joint European Society of Cardiology/American College of Cardiology Foundation/ American Heart Association/Word Heart Federation Task definition. NSTEACS was diagnosed according to the following criteria: typical chest pain and/or electrocardiographic changes without new ST elevation indicating myocardial ischemia with negative or elevated cardiac enzymes. Typical chest pain was evaluated as follows: more than 20 minutes in duration, new-onset angina, and an increase in its frequency and duration or severity STEMI diagnosis was based on typical chestpain and new ST-segment elevation at the J point in $\geq 2$ contiguous leads ( $\geq 0.2 \mathrm{mV}$ in $\mathrm{V} 1$ through $\mathrm{V} 3$ and $\geq 0.1 \mathrm{mV}$ in other leads). (According to the new definition; the J point is used to determine the magnitude of the ST-segment shift. New, or presumed new, J point elevation $0.1 \mathrm{mV}$ is required in all leads other than V2 and v3 Exclusion criteria were as follows: thrombolytic treatment within 24 hours, any systemic inflammatory disease, any hematological disease including anemia ( $<12 \mathrm{~g} / \mathrm{dL}$ for females, $<13 \mathrm{~g} / \mathrm{dL}$ for male), malignancies, renal and/or hepatic failure, recent infection, and history of blood transfusion in the last 3 months. The study protocol was approved by the local ethics committee and informed consent was obtained from all patients.

All patients will be subjected to the following detailed full history, thorough clinical examination, 12-lead surface ECG.

Complete transthoracic echocardiography, Peripheral venous blood samples of the patients were obtained upon their admission to the hospital.

The levels of blood biochemical parameters including baseline lipid panel, glucose, creatinine, creatine kinase, creatine kinase- $\mathrm{MB}$ and troponin levels were measured.

Samples for the complete blood count (CBC) analysis were collected in EDTAanticoagulated Monovettew tubes. 
An automated blood cell counter was used for measuring the $\mathrm{CBC}$ parameters including hemoglobin, white blood cell, neutrophil, lymphocyte, monocyte, platelet counts.

\subsection{Primary PCI Procedure}

All patients diagnosed with ACS received $300 \mathrm{mg}$ aspirin and $600 \mathrm{mg}$ clopidogrel loading dose at the hospital admission, and $70 \mathrm{IU} / \mathrm{kg}$ unfractionated heparin during PCI processing.

Primary PCI was performed to only culprit artery except for cardiogenic shock. The standard Judkins technique was used to perform the baseline coronary angiography.

We assessed the thrombus grade after restoring ante grade flow through guide wire or small balloon dilatation.

Angiographic thrombus burden was classified as previously defined by the thrombolysis in myocardial infarction (TIMI) study group [6].

Grade 0: no evidence of thrombus.

Grade 1: suspected thrombus (low contrast density, haziness, irregular lesion contour, or a smooth convex meniscus at the site of occlusion).

Grade 2: definite thrombus and the thrombus greatest dimension is _ $1 / 2$ vessel diameter.

Grade 3: definite thrombus and the thrombus greatest dimension $>1 / 2$ to $<2$ vessel diameters.

Grade 4: definite thrombus and the thrombus greatest dimension $>2$ vessel diameters.

Grade 5: total thrombotic occlusion.

The patients were grouped into 2 categories of low thrombus burden (grades 0 - 3) and high thrombus burden (Grades 4 and 5).

\subsection{Statistical Analysis}

Analysis of data was done by SPSS (ver. 20.0; IBM, Chicago, IL, USA). Quantitative data was displayed in the form of mean \pm standard deviation (SD). Qualitative data was demonstrated through Figures 1-5 of frequency and percentage. Charts were be used to illustrate data and relations where appropriate and $\mathrm{p}<$ 0.05 was accepted as indicating statistical significance.

\section{Results}

In Table 1 a total of 138 patients with acute coronary syndrome disease were included in the study, patients had a mean age of $(51.14 \pm 9.02)$ years, with male predominance $(67.4 \%)$. Nearly half of them $(50.7 \%)$ had high grade thrombus and the rest $(49.3 \%)$ had low grade thrombus. According to the basic clinical characteristics, (60.1\%) were hypertensive, $(50 \%)$ were diabetics $(48.6 \%)$ smokers and (31.9) had dyslipidemia. About (68.1\%) had one vessel affection, (21.7\%) had two vessels and $(10.1 \%)$ had three vessels affection. More than half of them (57.2\%) had ST segment elevation and (87\%) had positive troponin. 


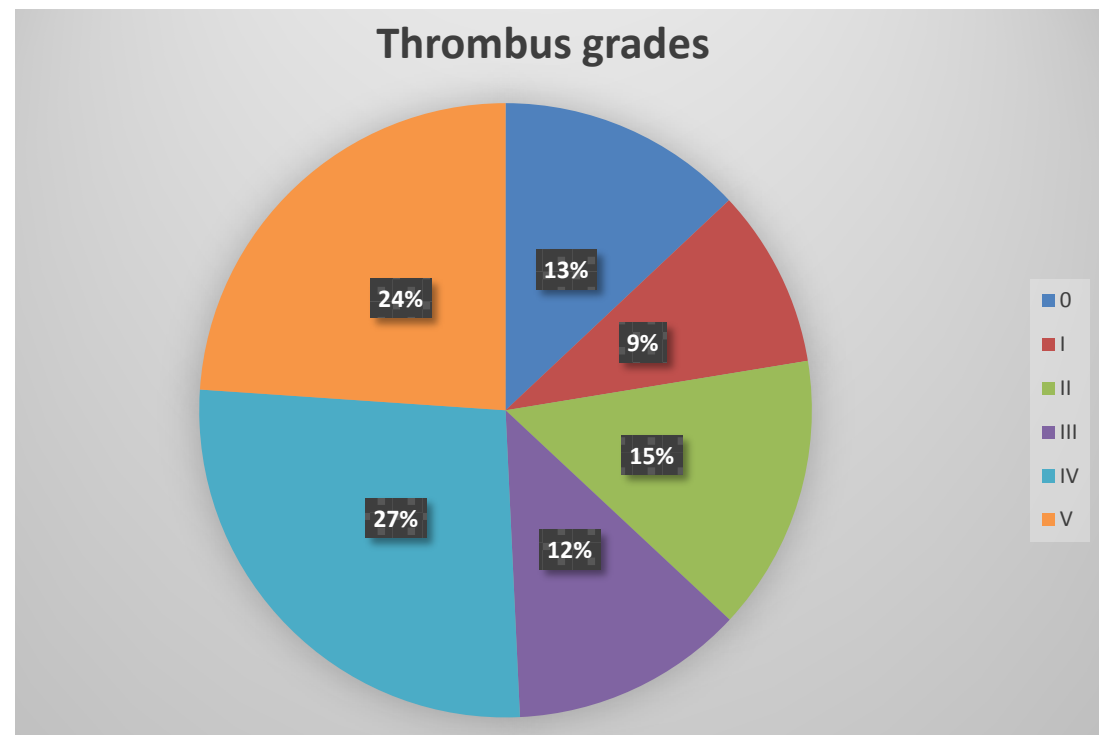

Figure 1. Thrombus grades distribution among studied patients.

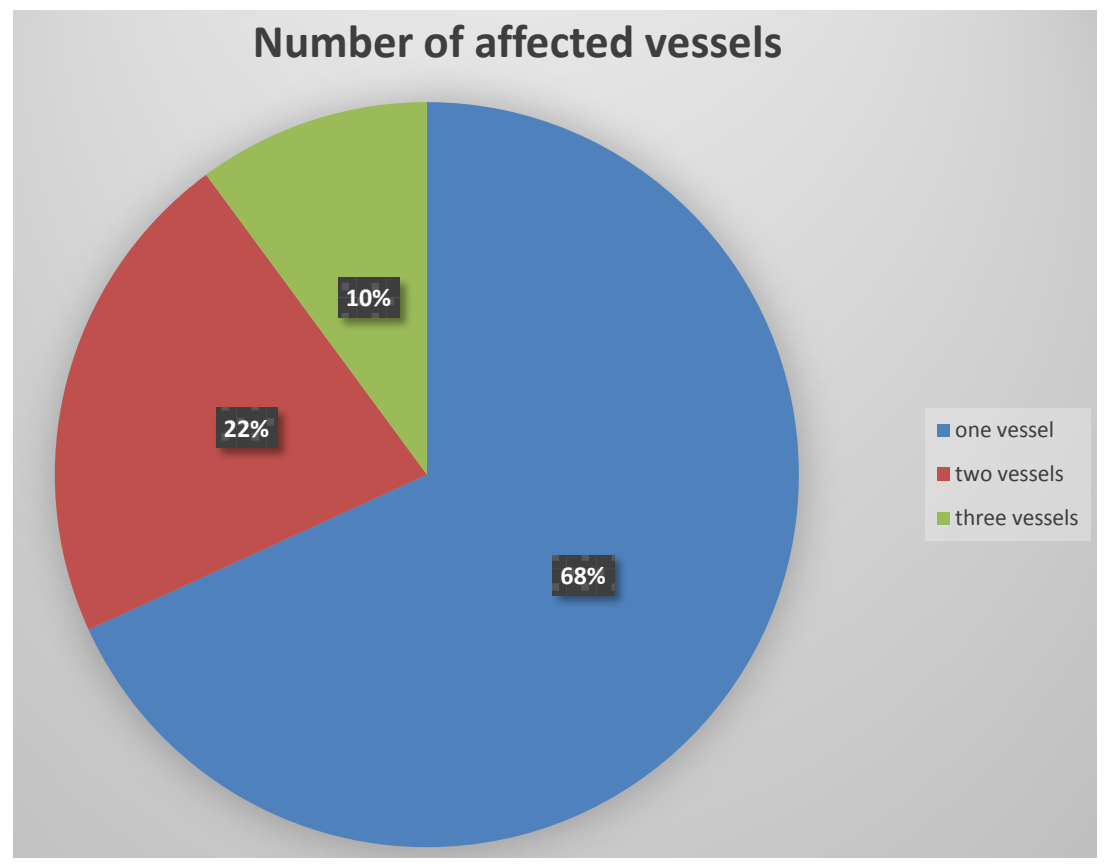

Figure 2. Number of affected vessels among patients.

Table 1. Baseline clinical characteristics of the study population.

\begin{tabular}{lccc}
\hline & & $\mathrm{N}=138$ & $\%$ \\
\hline Age & Range & \multicolumn{2}{c}{$38-68$} \\
& Mean \pm SD & \multicolumn{2}{c}{$51.14 \pm 9.02$} \\
Sex & & \multicolumn{2}{c}{} \\
& Female & & 32.6 \\
& Male & 45 & 67.4 \\
HTN & & 93 & 60.1 \\
\hline
\end{tabular}




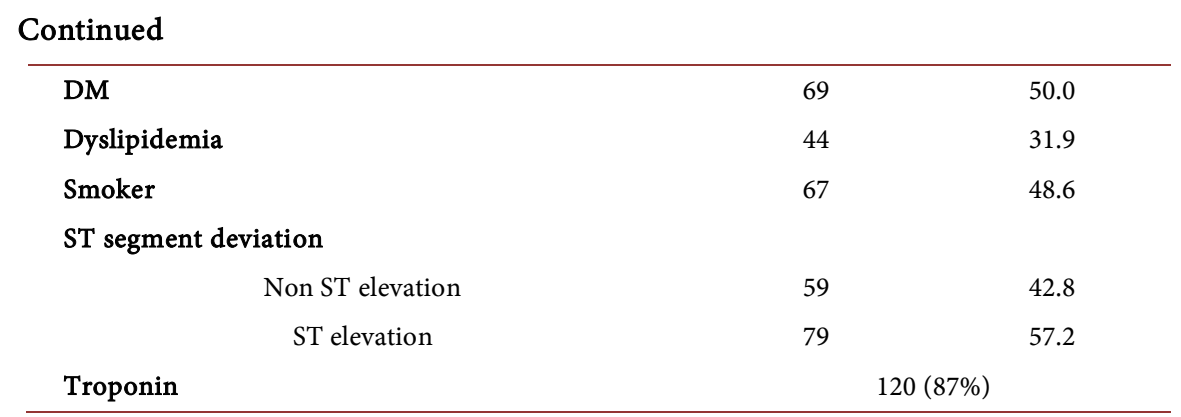

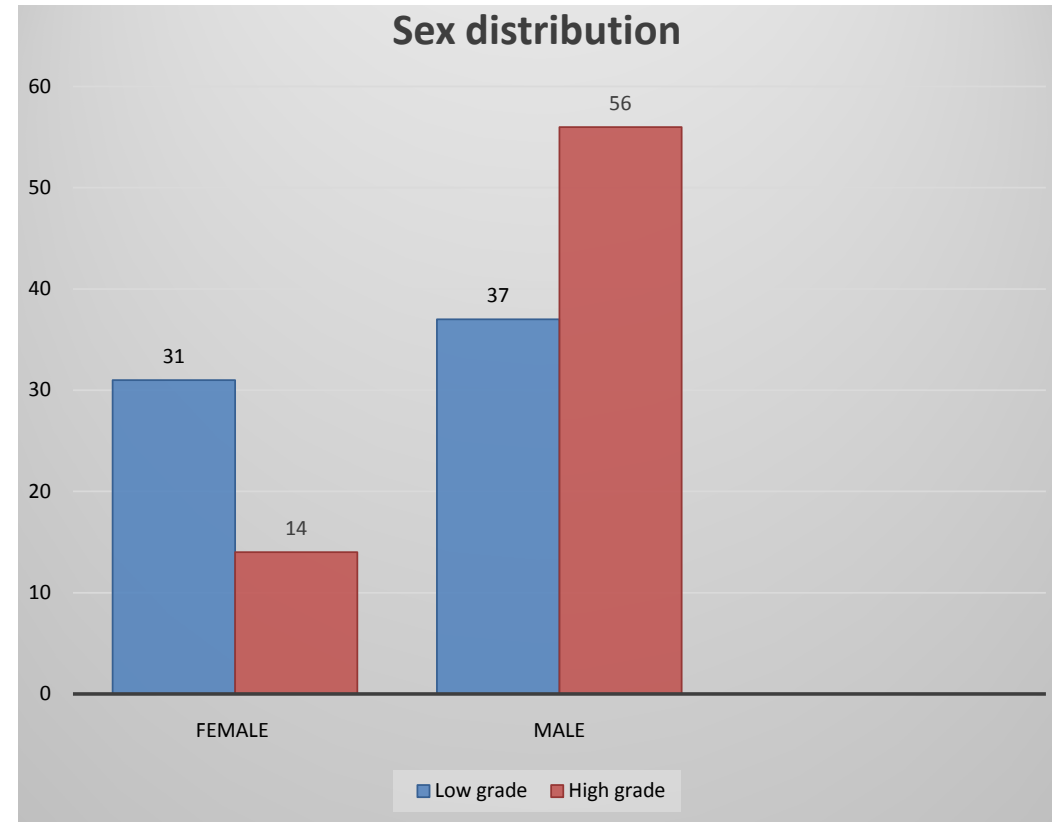

Figure 3. Sex distribution among study groups.

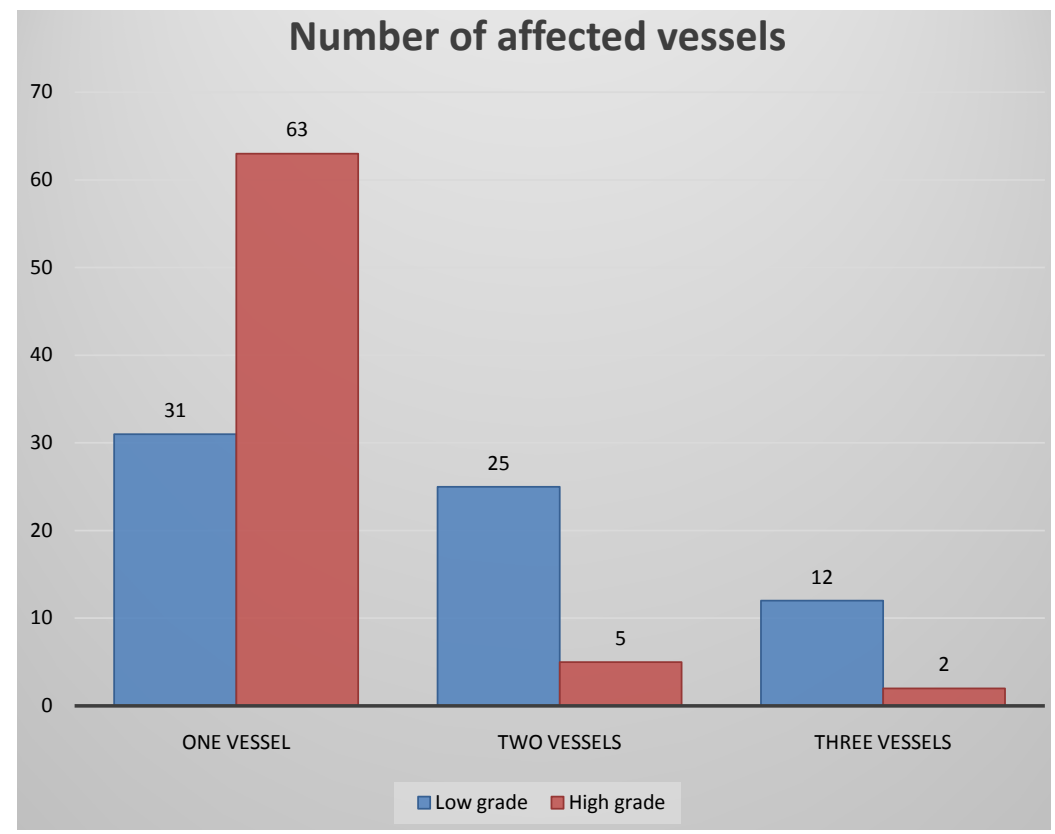

Figure 4. Number of affected vessels distribution among study groups. 


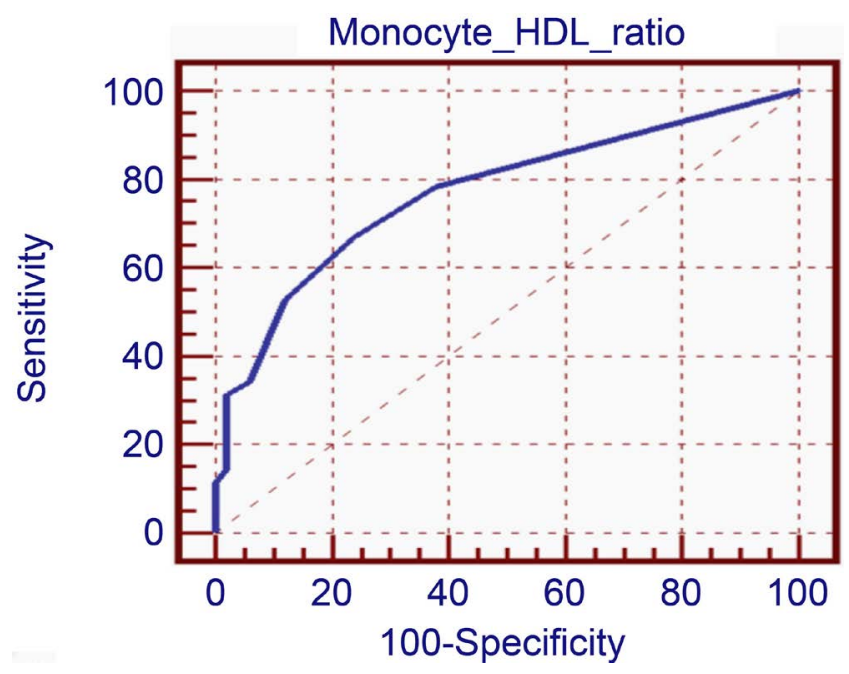

Figure 5. The receiver-operating characteristic (ROC) curve of monocyte count to high-density lipoprotein cholesterol ratio (MHR) for predicting of thrombus grade in acute coronary syndrome.

In Table 2, Nearly half of them (50.7\%) had high grade thrombus and the rest (49.3\%) had low grade thrombus, LAD culprit was (31.2\%), (68.1\%) had one vessel affection, $(21.7 \%)$ had two vessels and $(10.1 \%)$ had three vessels affection.

In Table 3, Their mean hemoglobin was (12.61 \pm 0.57$)$, WBCs (11.89 \pm 1.4$)$, platelet (261.09 \pm 68.77$)$, neutrophil (7.17 \pm 1.08$)$, monocyte (1.06 \pm 0.68$)$, lymphocyte $(3.25 \pm 0.52)$, triglyceride $(167.49 \pm 44.62)$, T-Cho (176.01 \pm 27.27$)$, creatinine $(0.94 \pm 0.19), \mathrm{EF}(43.8 \pm 11.41)$ and MHDL ratio $(0.03 \pm 0.02)$.

In Table 4, According to thrombus grade, study groups had statistical significant differences in sex, DM, LAD culprit, number of vessels involved. ST segment deviation and troponin result. Males were predominant in all thrombus grades more than females. Smokers and LAD culprit were statistically higher among high grade thrombus than low grade. (90\%) of high grade thrombus had one vessel affection while (45.6\%) of low grade had one vessel affection. High grade had significantly higher ST segment elevation (84.3\%) than low grade (29.4\%). All patients with high grade thrombus had troponin positive while (73.5\%) in low grade group had troponin positive.

In Table 5, study groups had statistical significant differences in WBCs, neutrophil, lymphocyte, Triglyceride, HDL, LDL, T-Cho, EF and Monocyte/HDL ratio. High grade group had higher means of diastolic blood pressure, WBCs, neutrophil, lymphocyte, and Triglyceride, T-Cho, EF and Monocyte/HDL ratio than low grade group. While low group had higher mean of HDL and LDL than high grade group

Table 6 showed that MHDL ratio had significant direct weak correlations with SBP, DBP, neutrophil, lymphocyte, T-Cho and LVESD. It also had significant direct strong correlation with WBCs and monocyte. MHDL ratio had significant direct intermediate correlation with triglyceride. While had significant indirect correlations with HDL-C, LDL-C and EF 
Table 2. Angiographic characteristics of the study population.

\begin{tabular}{lccc}
\hline & & $\mathrm{N}=138$ & $\%$ \\
\hline Thrombus Grade & 0 & 18 & 13.0 \\
& I & 13 & 9.4 \\
& II & 20 & 14.5 \\
& III & 17 & 12.3 \\
& IV & 37 & 26.8 \\
Thrombus burden & V & 33 & 23.9 \\
& Low & & \\
High & 68 & 49.3 \\
NuD Culprit & 1 & 70 & 50.7 \\
Number of affected vessels & 43 & 31.2 \\
& 2 & & \\
& 3 & 94 & 68.1 \\
\hline
\end{tabular}

Table 3. Laboratory characteristics of the study population.

\begin{tabular}{|c|c|c|}
\hline & Range & Mean \pm SD \\
\hline HGB & $10-15$ & $12.61 \pm 1.08$ \\
\hline WBCS & $8.82-14.88$ & $11.89 \pm 1.40$ \\
\hline Platelet & $187-480$ & $261.09 \pm 68.77$ \\
\hline Neutrophil & $6-8.3$ & $7.17 \pm 0.57$ \\
\hline Monocyte & $0.3-3.24$ & $1.06 \pm 0.68$ \\
\hline Lymphocyte & $2-4.3$ & $3.25 \pm 0.52$ \\
\hline Triglyceride & $120-290$ & $167.49 \pm 44.62$ \\
\hline HDL -C & $24-54$ & $36.70 \pm 6.60$ \\
\hline LDL -C & $100-154$ & $126.11 \pm 14.56$ \\
\hline T-Cho & $110-280$ & $176.01 \pm 27.27$ \\
\hline Creatinine & $0.6-1.3$ & $0.94 \pm 0.19$ \\
\hline LVEDD & $4.2-5.9$ & $5.18 \pm 0.51$ \\
\hline LVESD & $3-5$ & $4.15 \pm 0.62$ \\
\hline $\mathrm{EF}$ & $30-66$ & $43.80 \pm 11.41$ \\
\hline Monocyte/HDL ratio & $0.010-0.100$ & $0.03 \pm 0.02$ \\
\hline
\end{tabular}

Table 4. Baseline clinical and angiographic characteristics according to thrombus grade.

\begin{tabular}{|c|c|c|c|c|c|c|c|c|}
\hline & \multicolumn{8}{|c|}{ Thrombus Grade } \\
\hline & \multicolumn{2}{|c|}{$\begin{array}{c}\text { Low } \\
(\mathrm{N}=68)\end{array}$} & \multicolumn{2}{|c|}{$\begin{array}{c}\text { High } \\
(\mathrm{N}=70)\end{array}$} & \multicolumn{2}{|c|}{$\begin{array}{c}\text { Total } \\
(\mathrm{N}=138)\end{array}$} & \multicolumn{2}{|c|}{ Chi-square } \\
\hline & $\mathrm{N}$ & $\%$ & $\mathrm{~N}$ & $\%$ & $\mathrm{~N}$ & $\%$ & $\mathrm{X}^{2}$ & $\mathrm{P}$-value \\
\hline Age & 51.4 & 9.38 & 50.8 & 8.72 & & & 0.417 & 0.678 \\
\hline
\end{tabular}




\section{Continued}

\begin{tabular}{|c|c|c|c|c|c|c|c|c|}
\hline \multicolumn{9}{|l|}{ Sex } \\
\hline Female & 31 & 45.6 & 14 & 20.0 & 45 & 32.6 & \multirow{2}{*}{10.277} & \multirow{2}{*}{$<0.001^{* *}$} \\
\hline Male & 37 & 54.4 & 56 & 80.0 & 93 & 67.4 & & \\
\hline HTN & 39 & 57.4 & 44 & 62.9 & 83 & 60.1 & 0.436 & 0.509 \\
\hline $\mathrm{DM}$ & 43 & 63.2 & 26 & 37.1 & 69 & 50.0 & 9.393 & $0.002^{\star}$ \\
\hline Dyslipidemia & 23 & 33.8 & 21 & 30.0 & 44 & 31.9 & 0.232 & 0.630 \\
\hline Smoker & 29 & 42.6 & 38 & 54.3 & 67 & 48.6 & 1.871 & 0.171 \\
\hline LAD Culprit & 9 & 13.2 & 34 & 48.6 & 43 & 31.2 & 20.079 & $<0.001^{\star *}$ \\
\hline \multicolumn{9}{|l|}{ Number of vessel involved } \\
\hline 1 & 31 & 45.6 & 63 & 90.0 & 94 & 68.1 & \multirow{3}{*}{31.347} & \multirow{3}{*}{$<0.001^{\star *}$} \\
\hline 2 & 25 & 36.8 & 5 & 7.1 & 30 & 21.7 & & \\
\hline 3 & 12 & 17.6 & 2 & 2.9 & 14 & 10.1 & & \\
\hline \multicolumn{9}{|l|}{ ST segment deviation } \\
\hline Non ST elevation & 48 & 70.6 & 11 & 15.7 & 59 & 42.8 & \multirow{2}{*}{42.436} & \multirow{2}{*}{$<0.001^{* *}$} \\
\hline ST elevation & 20 & 29.4 & 59 & 84.3 & 79 & 57.2 & & \\
\hline \multicolumn{9}{|l|}{ Troponin } \\
\hline Negative & 18 & 26.5 & 0 & 0.0 & 18 & 13.0 & \multirow{2}{*}{21.309} & \multirow{2}{*}{$<0.001^{\star *}$} \\
\hline Positive & 50 & 73.5 & 70 & 100.0 & 120 & 87.0 & & \\
\hline
\end{tabular}

Table 5. Laboratory characteristics according to thrombus grade.

\begin{tabular}{|c|c|c|c|c|c|}
\hline & \multicolumn{5}{|c|}{ Thrombus Grade } \\
\hline & \multirow{2}{*}{$\begin{array}{c}\text { Low } \\
\text { Mean } \pm \text { SD }\end{array}$} & \multicolumn{2}{|c|}{ High } & \multicolumn{2}{|c|}{ T-test } \\
\hline & & Mean & $\pm \mathrm{SD}$ & $\mathrm{t}$ & P-value \\
\hline HGB & $12.74 \pm 1.07$ & 12.50 & \pm 1.08 & 1.297 & 0.197 \\
\hline WBCS & $10.95 \pm 1.24$ & 12.80 & \pm 0.82 & 10.411 & $<0.001^{\star \star}$ \\
\hline Platelet & $250.74 \pm 47.24$ & 271.16 & \pm 83.76 & 1.757 & 0.081 \\
\hline Neutrophil & $6.91 \pm 0.63$ & 7.43 & \pm 0.34 & 6.070 & $<0.001^{* *}$ \\
\hline Monocyte & $0.52 \pm 0.23$ & 1.59 & \pm 0.55 & 14.898 & $<0.001^{* *}$ \\
\hline Lymphocyte & $3.17 \pm 0.53$ & 3.32 & \pm 0.49 & 1.704 & 0.091 \\
\hline Triglyceride & $137.84 \pm 24.96$ & 196.29 & \pm 40.51 & 10.168 & $<0.001^{* *}$ \\
\hline HDL-C & $40.99 \pm 5.53$ & 32.53 & \pm 4.57 & 9.801 & $<0.001^{* *}$ \\
\hline LDL-C & $133.69 \pm 13.48$ & 118.74 & \pm 11.53 & 7.006 & $<0.001^{\star *}$ \\
\hline T-Cho & $170.97 \pm 22.03$ & 180.91 & \pm 30.91 & 2.171 & $0.032^{\star}$ \\
\hline Creatinine & $0.95 \pm 0.18$ & 0.93 & \pm 0.20 & 0.748 & 0.456 \\
\hline LVEDD & $5.14 \pm 0.60$ & 5.22 & \pm 0.41 & 0.952 & 0.343 \\
\hline LVESD & $4.08 \pm 0.74$ & 4.23 & \pm 0.49 & 1.395 & 0.165 \\
\hline $\mathrm{EF}$ & $46.78 \pm 14.27$ & 40.91 & \pm 6.60 & 3.113 & $0.002^{\star}$ \\
\hline Monocyte/HDL ratio & $0.014 \pm 0.008$ & 0.052 & \pm 0.019 & 14.842 & $<0.001^{\star *}$ \\
\hline
\end{tabular}


Table 6. Correlation between monocyte/HDL ratio and baseline clinical and angiographic characteristics.

\begin{tabular}{|c|c|c|}
\hline & \multicolumn{2}{|c|}{ Monocyte/HDL ratio } \\
\hline & $\mathrm{r}$ & P-value \\
\hline Age & -0.026 & 0.758 \\
\hline SBP & 0.252 & $0.003^{*}$ \\
\hline DBP & 0.226 & $0.008^{*}$ \\
\hline HGB & -0.084 & 0.325 \\
\hline WBCS & 0.728 & $<0.001^{* *}$ \\
\hline Platelet & -0.011 & 0.898 \\
\hline Neutrophil & 0.278 & $<0.001^{* *}$ \\
\hline Monocyte & 0.971 & $<0.001^{* *}$ \\
\hline Lymphocyte & 0.277 & $<0.001^{* *}$ \\
\hline Triglyceride & 0.604 & $<0.001^{* *}$ \\
\hline HDL-C & -0.725 & $<0.001^{* *}$ \\
\hline LDL-C & -0.391 & $<0.001^{* *}$ \\
\hline T-Cho & 0.212 & $0.013^{*}$ \\
\hline Creatinine & -0.096 & 0.262 \\
\hline LVEDD & 0.149 & 0.081 \\
\hline LVESD & 0.191 & $0.025^{*}$ \\
\hline $\mathrm{EF}$ & -0.278 & $<0.001^{* *}$ \\
\hline
\end{tabular}

Table 7 showed that the predictors of high thrombus grade were studied by multivariate logistic regression analysis. Sex $(\mathrm{OR}=0.159, \mathrm{p}=0.04), \mathrm{DM}(\mathrm{OR}=$ $0.159, \mathrm{p}=0.039)$, troponin $(\mathrm{OR}=0.256, \mathrm{p}=0.011)$, neutrophil $(\mathrm{OR}=0.242, \mathrm{p}=$ $0.002)$, monocyte $(\mathrm{OR}=0.957, \mathrm{p}<0.001)$, HDL-C $(\mathrm{OR}=0.039, \mathrm{p}<0.001)$, LDL-C $(\mathrm{OR}=0.003, \mathrm{p}=0.019)$ and MHDL ratio $(\mathrm{OR}=22.917, \mathrm{p}<0.001)$ were significant predictors.

Table 8 shows cutoff value of MHR was 0.02 with a sensitivity of $67.1 \%$, specificity of $76 \%$, PPV of $79.7 \%$, NPV of $62.3 \%$ and accuracy of $76.9 \%$.

\section{Discussion}

Inflammation and oxidative stress play important roles in atherosclerosis [7] Monocytes, which play substantial roles in immunity, activation, and cholesterol oxidation, are important milestones in the process. When activated monocytes interact with damaged endothelium, they secrete proinflammatory cytokines and adhesion molecules. Monocytes migrate to the subendothelium and differentiate into macrophages. The macrophage phagocytose oxidized lipoprotein particles and form foamy cells [8].

This study aimed to assess the relationship between MHR and thrombus burden in patients with Acute Coronary Syndrome. 
Table 7. Multivariate logistic regression analyses to detect the independent predictors of thrombus grade.

\begin{tabular}{|c|c|c|c|c|c|}
\hline & Odd ratio & 95\% Confidence & e Interval & $\mathbf{t}$ & P-value \\
\hline Sex & 0.159 & 0.007 & 0.310 & 2.078 & $0.040^{*}$ \\
\hline DM & 0.131 & 0.007 & 0.255 & 2.093 & $0.039^{*}$ \\
\hline LAD Culprit & 0.094 & 0.051 & 0.196 & 0.695 & 0.489 \\
\hline Number of vessel involved & 0.133 & 0.010 & 0.276 & 1.839 & 0.069 \\
\hline ST segment deviation & 0.077 & 0.066 & 0.219 & 1.066 & 0.289 \\
\hline Troponin & 0.256 & 0.059 & 0.452 & 2.582 & $0.011^{*}$ \\
\hline DBP & 0.004 & 0.001 & 0.008 & 0.232 & 0.817 \\
\hline WBCS & 0.053 & 0.040 & 0.134 & 0.860 & 0.392 \\
\hline Neutrophil & 0.242 & 0.090 & 0.393 & 3.156 & $0.002^{*}$ \\
\hline Monocyte & 0.957 & 0.583 & 1.330 & 5.082 & $<0.001^{* *}$ \\
\hline Triglyceride & 0.000 & 0.002 & 0.001 & 0.111 & 0.912 \\
\hline HDL-C & 0.039 & 0.024 & 0.054 & 5.052 & $<0.001^{* *}$ \\
\hline LDL-C & 0.003 & 0.001 & 0.007 & 2.383 & $0.019^{*}$ \\
\hline T-Cho & 0.002 & 0.000 & 0.002 & 0.350 & 0.727 \\
\hline $\mathrm{EF}$ & 0.004 & 0.002 & 0.007 & 0.682 & 0.497 \\
\hline Monocyte/HDL ratio & 22.917 & 11.181 & 34.654 & 3.873 & $<0.001^{* *}$ \\
\hline
\end{tabular}

Dependent Variable: Thrombus Grade.

Table 8. Validity of MHDL ratio for thrombus grade.

\begin{tabular}{cccccc}
\hline Cut off & Sens. & Spec. & PPV & NPV & Accuracy \\
\hline$>0.02^{*}$ & 67.1 & 76.0 & 79.7 & 62.3 & 76.9 \\
\hline
\end{tabular}

This prospective study included 138 patients with ACS JUNE 2018 to APRIL 2019 who were admitted to CCU department in National Heart Institute. The patients were grouped into 2 groups: Group of low thrombus burden (grades 0 3 ) and group of high thrombus burden (grades 4 and 5).

This study patients had a mean age of $(51.14 \pm 9.02)$ years, male patients had predominance (67.4\%) over females (32.6\%). Nearly half of them $(50.7 \%)$ had high grade thrombus and the rest $(49.3 \%)$ had low grade thrombus. According to the basic clinical characteristics, $(60.1 \%)$ were hypertensive, $(50 \%)$ were diabetics (48.6\%) smokers and (31.9) had dyslipidemia. About (68.1\%) had one vessel affection, $(21.7 \%)$ had two vessels and $(10.1 \%)$ had three vessels affection. More than half of them (57.2\%) had ST segment elevation and (87\%) had positive troponin.

According to thrombus grade, our study groups had statistical significant differences in sex, DM, LAD culprit, number of vessels involved. ST segment deviation and troponin result. Males were predominant in all thrombus grades more than females. Smokers and LAD culprit were statistically higher among high 
grade thrombus than low grade. (90\%) of high grade thrombus had one vessel affection while (45.6\%) of low grade had one vessel affection. High grade had significantly higher ST segment elevation (84.3\%) than low grade (29.4\%). All patients with high grade thrombus had troponin positive while $(73.5 \%)$ in low grade group had troponin positive.

This is similar to Kızıltunç et al., (2017) study [9] about "relationship between monocyte/high-density lipoprotein cholesterol ratio and angiographic severity and extent of coronary artery disease" in which a total of 760 patients who underwent coronary angiography were included in the study. The severity of coronary atherosclerosis was calculated by the severity score, and the patients were grouped as having low $(<20)$ and high $(>20)$ severity scores. Patients were aged $60.5 \pm 11.7$ years in the study population, and $460(60.5 \%)$ were males. Of these, 441 patients (mean age $58.2 \pm 11.5$ years, $53.5 \%$ males) were enrolled in Group 1 and 319 patients (mean age $63.8 \pm 11.2$ years, $70.2 \%$ males) were enrolled in Group 2 ( $\mathrm{p}<0.001$ ). Hypertension, diabetes mellitus, hyperlipidaemia, advanced age and smoking were more common in patients with high Gensini scores, as expected $(\mathrm{p}<0.05)$.

In addition, Nazowa et al. (2010) [10] have demonstrated the association between the circulating monocyte count and coronary plaque progression after acute coronary syndrome

Our study found that MHDL ratio had significant indirect correlations with HDL-C, LDL-C and EF. This is in agreement with Kızıltunç et al., (2017) [9] who reported that Ejection fraction, HDL levels and platelet count were significantly higher in patients with a low severity score than in those with a high severity score

On the other hand, HDL-cholesterol represents wellknown anti-inflammatory and antioxidant as well as antithrombotic effects; these activities have been shown in accordance with both the quality and quantity of HDL-C. As well, HDL-cholesterol has a close interaction with monocytes through suppressing monocyte activities, interrupting differentiation of monocytes to macrophages which results in a restricted inflammatory response (Murphy et al., 2008) [11].

But Kızıltunç et al., (2017) [9] study demonstrated a positive but weak correlation between MHR and increased coronary atherosclerotic burden

To the best of our knowledge, the current study is the first study to calculate the cutoff value of MHR for thrombus burden in patients with acute coronary artery disease was 0.02 with a sensitivity of $67.1 \%$, specificity of $76 \%$, PPV of $79.7 \%$, NPV of $62.3 \%$ and accuracy of $76.9 \%$.

While Cetin et al., (2016) [12] found that in ROC analysis, a MHR cut-off of 144.3 had $80.2 \%$ sensitivity and $69.8 \%$ specificity for prediction of in-hospital MACE (AUC $=0.770,95 \mathrm{CI} \%: 0.745-0.795, \mathrm{p}<0.001$ ). Also, a MHR cut-off value of 142.9 had $81.5 \%$ sensitivity and $71.2 \%$ specificity for prediction of long-term MACE (AUC = 0.806, 95CI\%: $0.785-0.827, \mathrm{p}<0.001$ ).

Our study has some limitations as we could not assess all potential factors that might involve the interaction between monocytes and HDL particles. Monocytes 
are not homogenous in behavioural response and have various types demonstrating different activities (Woollard and Geissmann, 2010). The classification of different monocyte subgroups may strengthen our results. The same situation also exists in HDL particles. Beyond the quantity of HDL particles, HDL particles can be classified based on size such as small, intermediate and large HDL subtypes. The evaluation of atherogenic properties of these subtypes may have a contributed to our study. Determination of Apo A1 level and Apo E, which are major components of HDL's anti-inflammatory properties, may give our results greater precision (Kontush and Chapman, 2006) [13]. In addition, our study was a single centre study and also we assessed only MHR on admission. Evaluation of the temporal trend of MHR in ACS and during the follow-up period may provide a different point-of-view.

\section{Conclusion}

MHR as a novel marker is indicated to be an independent predictor of thrombus burden of coronary artery disease and future cardiovascular events in patients with ACS.

\section{Study Limitations}

This study has several limitations. Its primary limitations are that it was a single-center study with a small study population.

Another limitation is that we analyzed only the admission MHR, and the MHR may change after the acute phase of ACS. We also assessed the thrombus burden visually, and a quantitative method would have been better.

\section{Conflicts of Interest}

The authors declare no conflicts of interest regarding the publication of this paper.

\section{References}

[1] Sianos, G., Papafaklis, M.I., Daemen, J., et al. (2007) Angiographic Stentthrombosis after Routine Use of Drug-Eluting Stents in ST-Segment Elevation Myocardial Infarction: The Importance of Thrombus Burden. Journal of the American College of Cardiology, 50, 573-583. https://doi.org/10.1016/j.jacc.2007.04.059

[2] Sianos, G., Papafaklis, M.I. and Serruys, P.W. (2010) Angiographic Thrombus Burden Classification in Patients with ST-Segment Elevation Myocardial Infarction Treated with Percutaneous Coronary Intervention. Journal of Invasive Cardiology, 22, 6B-14B.

[3] Singh, M., Berger, P.B., Ting, H.H., et al. (2001) Influence of Coronary Thrombus on Outcome of Percutaneous Coronary Angioplasty in the Current Era (the Mayo Clinic Experience). American Journal of Cardiology, 88, 1091-1096.

https://doi.org/10.1016/S0002-9149(01)02040-9

[4] Tanboga, I.H., Topcu, S., Aksakal, E., Kalkan, K., Sevimli, S. and Acikel, M. (2014) Determinants of Angiographic Thrombus Burden in Patients with ST-Segment Elevation Myocardial Infarction. Clinical and Applied Thrombosis/Hemostasis, 20, 716- 


\section{2. https://doi.org/10.1177/1076029613483169}

[5] Hamur, H., Duman, H., Bakirci, E.M., et al. (2016) Bilirubin Levels and Thrombus Burden in Patients with ST-Segment Elevation Myocardialinfarction. Angiology, 67, 565-570. https://doi.org/10.1177/0003319715603899

[6] Gibson, C.M., de Lemos, J.A., Murphy, S.A., et al. (2001) Combination Therapy with Abciximab Reduces Angiographically Evident Thrombus in Acute Myocardial Infarction: A TIMI 14 Substudy. Circulation, 103, 2550-2554. https://doi.org/10.1161/01.CIR.103.21.2550

[7] Akpek, M., Elcik, D., Kalay, N., et al. (2013) The Prognostic Value of Serum Gamma Glutamyl Transferase Activity on Admission in Patients with STEMI Undergoing Primary PCI. Angiology, 63, 579-585. https://doi.org/10.1177/0003319711431880

[8] Ghattas, A., Griffiths, H.R., Devitt, A., et al. (2013) Monocytes in Coronary Artery Disease and Atherosclerosis: Where Are We Now? Journal of the American College of Cardiology, 62, 1541-1551. https://doi.org/10.1016/j.jacc.2013.07.043

[9] Kundi, H., Kiziltunc, E., Cetin, M., et al. (2016) Association of Monocyte/HDL-C Ratio with SYNTAX Scores in Patients with Stable Coronary Artery Disease. Herz, 41, 523-529. https://doi.org/10.1007/s00059-015-4393-1

[10] Nozawa, N., Hibi, K., Endo, M., Sugano, T., Ebina, T., Kosuge, M., et al. (2010) Association between Circulating Monocytes and Coronary Plaque Progression in $\mathrm{Pa}$ tients with Acute Myocardial Infarction. Circulation Journal, 74, 1384-1391. https://doi.org/10.1253/circj.CJ-09-0779

[11] Antman, E.M., Wiviott, S.D., Murphy, S.A., et al. (2008) Early and Late Benefits of Prasugrel in Patients with Acute Coronary Syndromes Undergoing Percutaneous Coronary Intervention: A TRITON-TIMI 38 (Trial to Assess Improvement in Therapeutic Outcomes by Optimizing Platelet Inhibition with Prasugrel-Thrombolysis in Myocardial Infarction) Analysis. Journal of the American College of Cardiology, 51, 2028-2033.

[12] Cetin, M.S., Ozcan Cetin, E.H., Kalender, E., Aydin, S., Topaloglu, S., Kisacik, H.L. and Temizhan, A. (2016) Monocyte to HDL Cholesterol Ratio Predicts Coronary Artery Disease Severity and Future Major Cardiovascular Adverse Events in Acute Coronary Syndrome. Heart, Lung and Circulation, 25, 1077-1086.

[13] Davidson, W.S., Silva, R.A., Chantepie, S., Lagor, W.R., Chapman, M.J. and Kontush, A. (2009) Proteomic Analysis of Defined HDL Subpopulations Reveals Particle-Specific Protein Clusters: Relevance to Antioxidative Function. Arteriosclerosis, Thrombosis, and Vascular Biology, 29, 870-876.

https://doi.org/10.1161/ATVBAHA.109.186031 